Eixo Temático: Biologia Aplicada

\title{
ET-09-017 \\ EFICIÊNCIA DE ARMADILHAS ADESIVAS DE COR AMARELA NA CAPTURA DE ARTRÓPODES NOS SISTEMAS CONVENCIONAL E ORGÂNICO DE HORTALIÇAS
}

Averlane Vieira da Silva ${ }^{1}$, Elayne Barbosa de Oliveira ${ }^{1}$, Fernanda Stefanny Lima Sobrinho ${ }^{1}$, Isabelle Cristina Santos Magalhães ${ }^{1}$, Mayara Camila Santos Silva ${ }^{1}$, Rubens Pessoa de Barros²

1Universidade Estadual de Alagoas - UNEAL, Campus I. Rua Governador Luiz Cavalcante, S/N. Alto Cruzeiro. Arapiraca-AL. (CEP: 57312-000). Graduandos em Ciências Biológicas. UNEAL Campus I. E-mail: averlanewest@hotmail.com.

${ }^{2}$ Departamento de Ciências Biológicas. Universidade Estadual de Alagoas - UNEAL Campus I.

http://dx.doi.org/10.21472/congrebio2016.et-09-017

\section{RESUMO}

O Brasil ocupa a $13^{\mathrm{a}}$ posição mundial quanto à área destinada à agricultura orgânica, a incidência de pragas em campos de produção de hortaliças contribui para a menor produtividade e consequente queda, que pode superar em $60 \%$ da produção total. O monitoramento das pragas é fundamental para embasar o controle, pois permite acompanhar a incidência e os danos das pragas. Diante disso, a referente pesquisa teve como objetivo avaliar a eficiência de armadilha adesiva de cor amarela em dois sistemas de cultivo de hortaliças, um orgânico e outro convencional na região agreste de Alagoas, além de identificar em nível de ordem e família os artrópodes coletados. As coletas semanais e contagem dos insetos foi feita durante 9 semanas, realizadas, no período de dois meses. Verificou-se um total de 3.372 artrópodes distribuídos em 9 ordens e 24 famílias nos dois sistemas, sendo 600 no cultivo orgânico, com 9 ordens distribuídos em 24 famílias, no convencional foram encontrados 2.772 distribuídos em 6 ordens e 13 famílias. Foi calculado os índices de Simpson para a diversidade e Margalef para o índice de riqueza. Os resultados foram submetidos à análise pelo teste DivEs - Diversidade de Espécies. No cultivo orgânico o índice de Simpson foi de 0.84 e no convencional 0.15. O índice de Margalef para riqueza, no cultivo orgânico foi 2,86 e no convencional 2,69. Verifica-se que no sistema com o manejo agroecológico, os índices se mostram favoráveis ao equilíbrio.

Palavras-chave: Armadilha Adesiva Colante; Artrópodes; Índice de Simpson e Margalef.

\section{INTRODUÇÃO}

O Brasil ocupa a $13^{a}$ posição mundial quanto à área destinada à agricultura orgânica certificada, com mais de 275 mil hectares. Dentre os alimentos produzidos, destacam-se as olerícolas para o mercado interno (TRIVELLATO e FREITAS, 2003). Em Alagoas segundo o Censo Agropecuário, o Estado ocupa uma área total de 1.905.266 ha agropecuário (IBGE, 2006).

A incidência de pragas em campos de produção de hortaliças contribui para a menor produtividade e consequente queda, que pode superar em $60 \%$ da produção total em casos como tomate e repolho (BARBOSA e FRANÇA, 1980; CASTELO BRANCO e GUIMARÃES, 1990).

Conforme a relação com o homem, os artrópodes podem ser classificados como benéficos ou prejudiciais. Muitos são benéficos, seja atuando como inimigos naturais de espécies prejudiciais ou atuando como polinizadores de plantas cultivadas, ou ainda, produzindo materiais de valor como mel e seda. Somente num agroecossistema mais complexo e diversificado poderá existir potencial para interações benéficas; essa diversificação conduz a 
modificações positivas nas condições abióticas e atrai populações de artrópodes benéficos, regulando assim, a população de pragas (GLIESSMAN, 2000).

O monitoramento das pragas é fundamental para embasar o controle, pois permite acompanhar a incidência e os danos das pragas, facilitando a tomada de decisão de controle no momento adequado. A primeira etapa do controle é o reconhecimento dos insetos praga e seus inimigos naturais (SANTOS, 2007a). O controle químico, de modo geral, não deve ser preventivo, procurando-se sempre que possível levar em conta os níveis populacionais e o nível de dano de cada inseto-praga e sua capacidade de causar prejuízos.

Devido à exigência dos consumidores por produtos sem resíduos e mais saudáveis, há uma tendência de diminuição do número de aplicações e de inseticidas disponíveis no mercado. Por isso, outros métodos de controle menos agressivos e dispendiosos devem ser adotados (Santos, 2007b). Um desses métodos consiste em adotar armadilhas adesivas coloridas para realizar o monitoramento e o controle dos insetos-pragas.

\section{OBJETIVO}

Este trabalho teve como objetivo avaliar a eficiência de armadilhas adesivas de cor amarela na coleta de artrópodes em dois sistemas de cultivo de hortaliças, um orgânico e outro convencional na região agreste de Alagoas.

\section{MATERIAL E MÉTODOS}

O estudo foi realizado, no Sítio Bálsamo, rodovia AL-110 em Arapiraca-AL com as seguintes coordenadas geográficas $9^{\circ} 77^{\prime} 58^{\prime}$ ' S e $36^{\circ} 59^{\prime} 23^{\prime}$ ' W, sistema convencional e no povoado Bom Jardim, próximo à rodovia AL 220 com as coordenadas geográficas $9^{\circ} 81^{\prime} 76^{\prime \prime} \mathrm{S}$ e 36 59' 42'” W, sistema orgânico. A coleta foi realizada durante os meses de fevereiro a abril de 2016.

As áreas apresentam um total de aproximadamente 3,0 ha, com irrigação feita por gotejamento. No cultivo orgânico apresenta uma variedade de 35 tipos de hortaliças destacamse, tomate, pimentão, alface, coentro e cenoura. Já no cultivo convencional apresenta uma variedade de 10 tipos de hortaliças dentre as quais existem o pimentão, tomate, coentro e abobrinha.

Para a captura dos insetos praga foram utilizadas armadilhas do tipo painel colante (Isca Tecnologias ${ }^{\circledR}$ ), de coloração amarela, com $25 \mathrm{~cm}$ de altura x $10 \mathrm{~cm}$ de largura, contendo cola adesiva nos dois lados. Cada armadilha apresenta em cada lado 40 quadrados de 2,5 cm x $2,5 \mathrm{~cm}$ totalizando 80 quadrados.

No cultivo orgânico e convencional foram postas duas armadilhas nas bordas das plantações. As armadilhas foram penduradas com o auxílio de nylon amarrados a duas estacas, numa altura aproximada de $1,0 \mathrm{~m}$ em relação à superfície do solo, conforme a figura 1 . As coletas foram realizadas a cada sete dias, e as armadilhas substituídas. Os artrópodes foram levados para o laboratório da Universidade Estadual de Alagoas, retirados das armadilhas com auxílio de uma pinça, contados, e colocados em recipientes de plástico com capacidade de 60 $\mathrm{mL}$ álcool a $70 \%$, etiquetados com as devidas identificações de cada armadilha para o procedimento da identificação em nível de ordem e família, conforme a figura 2. Os resultados foram obtidos submetidos à análise pelo teste DivEs - Diversidade de Espécies. 


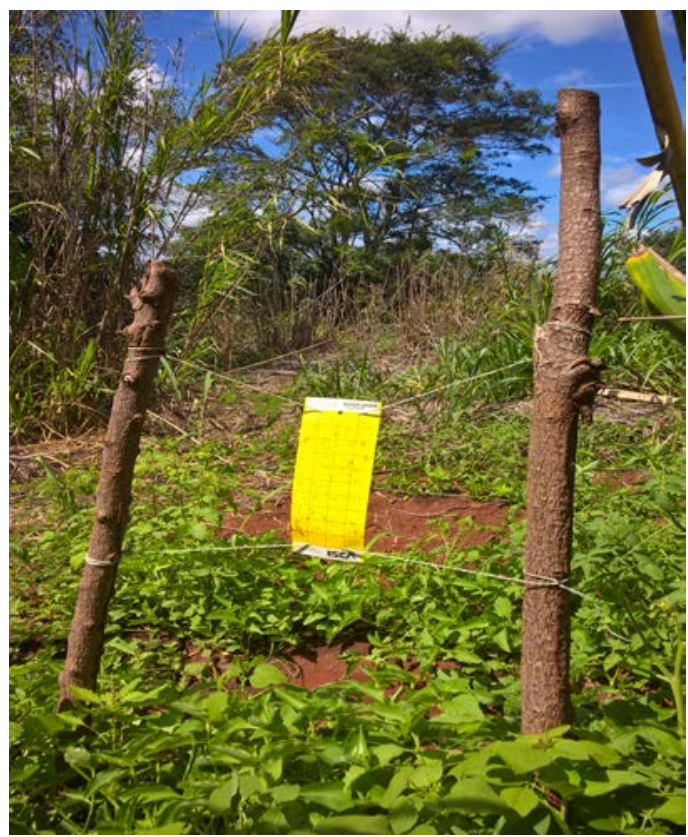

Figura 1. Posicionamento das armadilhas do tipo painel colante de cor amarela.

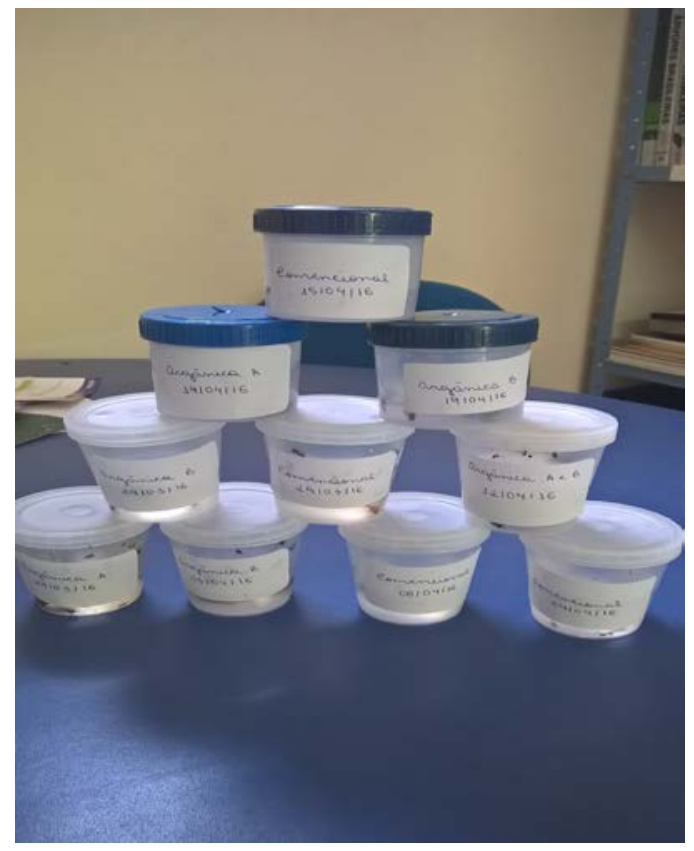

Figura 2. Potes de identificação dos artrópodes depositados no laboratório da Universidade Estadual de Alagoas.

\section{RESULTADO E DISCUSSÕES}

Nos dois sistemas de cultivo foram coletados cerca de 3.372 artrópodes, sendo 600 no cultivo orgânico, com 9 ordens distribuídos em 24 famílias, no convencional foram encontrados 2.772 distribuídos em 6 ordens e 13 famílias. As ordens foram: Araneae, Blattaria, Coleoptera, Diptera, Hemiptera, Hymenoptera, Lepidoptera, Orthoptera e Thysanoptera. 
Os representantes de artrópodes que ocorreram em maior número para as áreas do cultivo convencional e orgânico corresponderam a Ordem Thysanoptera e Família Thripidae no total de 2.333 no cultivo convencional e 199 no orgânico. Os espécimes dessa família vivem em flores ou alimentam-se de folhas, poucos são predadores (MOUND e MURULLO, 1996).

Nos levantamentos houve diferença, não significativa quando comparadas com os índices das coletas 1 do sistema convencional e 4 do sistema orgânico. Em vista que, o índice de diversidade de Simpson no geral variou de 0,30 no cultivo convencional a 0,78 no cultivo orgânico.

No índice de riqueza Margalef houve uma variação de 2,14 no cultivo convencional a 2,30, no cultivo orgânico. A tabela 1 e 2 representam os resultados de artrópodes coletados com seus respectivos valores nos índices de diversidade e riqueza.

Tabela 1. Índice de diversidade de artrópodes no cultivo convencional.

\begin{tabular}{|c|c|c|c|}
\hline Levantamento & Total de indivíduos & Diversidade e riqueza & Índice \\
\hline \multirow[t]{2}{*}{ 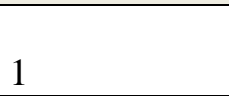 } & \multirow[b]{2}{*}{1086} & Simpson & 0,1559 \\
\hline & & Margalef & 2,8601 \\
\hline \multirow[b]{2}{*}{2} & \multirow[b]{2}{*}{889} & Simpson & 0,3091 \\
\hline & & Margalef & 2,2077 \\
\hline \multirow[b]{2}{*}{3} & \multirow[b]{2}{*}{529} & Simpson & 0,3015 \\
\hline & & Margalef & 2,0081 \\
\hline \multirow[b]{2}{*}{4} & \multirow[b]{2}{*}{268} & Simpson & 0,3141 \\
\hline & & Margalef & 1,5166 \\
\hline
\end{tabular}

Tabela 2. Índice de diversidade de artrópodes no cultivo orgânico.

\begin{tabular}{l|l|l|l}
\hline Levantamento & Total de indivíduos & Diversidade e riqueza & Índice \\
\hline \multirow{2}{*}{1} & \multirow{3}{*}{2} & $\begin{array}{l}\text { Simpson } \\
\text { Margalef }\end{array}$ & 0,8486 \\
\cline { 3 - 4 } 2 & 153 & Simpson & 2,6931 \\
\cline { 3 - 4 } 3 & \multirow{3}{*}{4} & Margalef & 0,7892 \\
\hline \multirow{2}{*}{4} & 121 & Simpson & 2,4236 \\
\cline { 3 - 4 } & \multirow{2}{*}{198} & Margalef & 0,7881 \\
\hline & & Simpson & 0,6326 \\
\cline { 3 - 4 } & & Margalef & 1,4709 \\
\hline
\end{tabular}

O índice de Simpson mostra uma maior dominância e menor equidade na primeira coleta do cultivo convencional e a quarta do cultivo orgânico. Esse resultado pode ser devido à ocorrência de um número 83 indivíduos da Ordem Thysanoptera da Família Tripidae no cultivo orgânico, além de, 1.074 correspondentes a mesma ordem e família no cultivo convencional. O índice de dominância de Simpson é derivado de índices heterogêneos que medem os pesos das espécies abundantes mais comuns em uma comunidade (Dias, 2004).

O índice de riqueza de Margalef foi maior no sistema convencional 2,8601 e no orgânico 2,6931, o que representa uma riqueza intermediária, uma vez que, abaixo de dois é considerada baixa e acima de cinco uma diversidade alta. Segundo Melo et al. (2003), a comparação entre a riqueza de espécies de diferentes assembleias usando-se amostras com tamanhos diferentes pode produzir conclusões errôneas devido à forte relação positiva entre riqueza e esforço de amostragem. 


\section{CONCLUSÃO}

A riqueza e diversidade em ambos os cultivos evidenciam que as armadilhas adesivas de cor amarela são eficientes na captura de artrópodes.

A quantidade de espécimes coletados foi satisfatória, e mostra qual o manejo e qual a tomada de decisão quanto às medidas de controle a serem utilizadas. à temática.

Será necessário repetir essa metodologia para que seja feita outras avaliações referentes

\section{REFERÊNCIAS}

BARBOSA, S.; FRANÇA, F.H. As pragas do tomateiro e seu controle. Informe Agropecuário, v. 6, p. 37-40, 1980.

DIAS, S. C. Planejando estudos de diversidade e riqueza: uma abordagem para estudantes de graduação. Acta Scientiarum, v. 26, p. 373-379, 2004.

GLIESSMAN, S. Agroecologia: processos ecológicos em agricultura sustentável. Porto Alegre: Editora da Universidade/UFRGS, 2000.

GULLAN, P. J.; CRANSTON, P. S. Os insetos: um resumo de entomologia. 3. ed. São Paulo: Roca, 2008.

IBGE. Censo Agropecuário $2006 . \quad$ Disponível em: <ftp://ftp.ibge.gov.br/Censos/Censo_Agropecuario_2006/>. Acesso em: 26 abr. 2016.

MELO, A. S. Diversidade de macroinvertebrados aquáticos em riachos. In: CULLEN Jr., L.; RUDRAN, R.; VALLADARES-PÁDUA, C. Métodos de estudo em Biologia da Conservação e manejo da vida silvestre. Curitiba: Ed. UFPR e Fundação O Boticário de Proteção à Natureza, 2003. p. 69-90.

MOUND, L. A.; MARULLO, R. The trips of central and South America: an introduction (Insecta: Thysanoptera). Florida: Associated Publishers, 1996.

SANTOS, J. P. Utilização de feromônio na agricultura. Agropecuária Catarinense, v. 20, p. 110, 2007a.

SANTOS, J. P. Monitoramento de pragas do tomateiro. Correio Lageano Rural, p. 2. 2007b.

TRIVELlATO, M. D.; FREITAS, G. B. Panorama da Agricultura Orgânica. In: STRINGUETA, P. C.; MUNIZ, J. N. Alimentos orgânicos: produção tecnologia e certificação. Viçosa: UFV, 2003. p. 9-35. 